\title{
ESTRATÉGIAS DE DISTÂNCIA TECNOLÓGICA NA ADOÇÃO DE TRANSFERÊNCIA DE TECNOLOGIA EM UMA INDÚSTRIA DE ALIMENTOS: UM ESTUDO DE CASO
}

\section{STRATEGIES OF TECHNOLOGICAL DISTANCE IN THE ADOPTION OF TECHNOLOGY TRANSFER IN A FOOD INDUSTRY: A CASE STUDY}

\author{
Luani Back ${ }^{1}$; João Luiz Kovaleski²; Pedro Paulo de Andrade Junior ${ }^{3}$ \\ ${ }^{1,2,3}$ Universidade Tecnológica Federal do Paraná - UTFPR - Ponta Grossa - Brasil luaniback@ hotmail.com
}

\begin{abstract}
Resumo
O presente artigo foi desenvolvido com o objetivo de determinar as dificuldades impostas pela distância tecnológica entre os agentes, fornecedor e receptor, em processos de transferência de tecnologia em uma indústria de alimentos. Inúmeras barreiras podem surgir neste tipo de processo, $e$ estas podem inibir ou restringir a adoção e a funcionalidade da nova tecnologia. A identificação destas dificuldades e a detecção das possíveis causas possibilitam a formulação de soluções que minimizem seus impactos. Para o desenvolvimento da pesquisa realizou-se coleta de dados através de pesquisa bibliográfica e documental, observações diretas e entrevistas com os gerentes da indústria de alimentos em questão. Os resultados do estudo de caso demonstram que a transferência de tecnologia está diretamente relacionada com a distância tecnológica entre os agentes de transferência. Estes resultados contribuem para o sucesso dos novos processos de transferência, em que o cenário da indústria pode ser adaptado de acordo com as exigências e a distância tecnológica entre fornecedor e receptor da tecnologia.
\end{abstract}

Palavras-chave: transferência de tecnologia; distância tecnológica; indústria de alimentos.

\section{Introdução}

A adoção de novas tecnologias podem gerar grandes alterações em uma empresa, tanto na estrutura organizacional, na alocação de recursos, distribuição de tarefas, como no comportamento das pessoas envolvidas. A transferência de tecnologia pode enfrentar diversas barreiras, que podem inibir ou restringir a adoção de uma nova tecnologia, assim como pode encontrar facilitadores que favorecem sua absorção.

Ao se transferir uma dada tecnologia, os conhecimentos criados em torno de práticas existentes na organização fornecedora passam a ser transferidos simultaneamente para a organização receptora. À medida que o processo de transferência dessa dada tecnologia avança 
mediante sua implantação, novos conhecimentos são criados, baseados na utilização recorrente dos conhecimentos provenientes das práticas existentes, eles são reforçados ou modificados e sustentados na atual realidade organizacional (OLIVEIRA e SEGATTO, 2009). Esses conhecimentos podem, ou não, apresentar os mesmos resultados da empresa que está fornecendo dependendo da similaridade entre as empresas e da gestão de conhecimentos no processo de transferência de tecnologia.

As organizações participantes de um processo de transferência de tecnologia podem apresentar realidades distintas, e assim suas distâncias tecnológicas podem interferir no sucesso da absorção da tecnologia e dos conhecimentos envolvidos. Podemos considerar distância como o intervalo entre dois pontos, seja ele geográfico ou cultural, que interferem na relação direta entre esses.

No desenvolvimento de uma tecnologia, consideram-se as características do local onde esse processo está ocorrendo, porém ao transferí-la o receptor poderá apresentar características distintas, tanto em relação às pessoas envolvidas como ao processo em que ela será inserida.

O processo de transferência de tecnologia sofre influências de diferentes fatores inerentes ao processo, que podem interferir ou impedir o sucesso desse processo. Dentro deste contexto é preciso conhecer as dificuldades para a transferência de tecnologia relacionadas à distância tecnológica entre seus agentes.

Este artigo tem por objetivo determinar as principais dificuldades impostas pela distância tecnológica entre os agentes de transferência de tecnologia em uma indústria de alimentos.

\section{Referencial teórico}

\section{Transferência de tecnologia}

Um dos requisitos para o sucesso de uma organização, seja ela de manufatura ou prestação de serviços, a tecnologia está presente com seus aspectos positivos e/ou negativos. Segundo Santos et al (1997), "tecnologia pode ser definida como o saber relativo aos meios servindo à realização de diversos fins que se propõem à atividade econômica". Podemos então considerar tecnologia como um conjunto de conhecimentos necessários para se conceber, produzir e distribuir bens e serviços de forma competitiva (KRUGLIANSKAS, 1996).

Quando um conjunto de conhecimentos, de habilidades e de procedimentos é transferido de uma organização para outra que então passa a dominar uma tecnologia que ela não produziu, Barbieri (1990) e Theotonio et al (2002) afirmam ter ocorrido transferência de tecnologia. Esse 
processo é fundamental para o crescimento e maturidade da maioria das instituições, pois assim são capazes de acompanhar as mudanças do mercado (LUNDQUIST, 2003).

A transferência de tecnologia (TT) não é um evento momentâneo, e sim um processo que ocorre em várias fases, e uma delas é o reconhecimento inicial de oportunidade/necessidade, por meio de busca, comparação, seleção, aquisição, implementação e uso a longo prazo, que compreende a aprendizagem e desenvolvimento (FREITAS et al., 2009). Para que sirva como um componente da sua estratégia de tecnologia, a empresa deve escolher o modo apropriado para adquirir a tecnologia necessária, ou seja, todas as opções disponíveis para uma empresa devem ser cuidadosamente consideradas, pois juntamente com a aquisição é preciso transferir o conhecimento tecnológico envolvido (HUNG e TANG, 2008).

Dentro de um processo de transferência de tecnologia há dois elementos internos: o agente transferidor e o agente receptor. Para que a TT ocorra de maneira efetiva é preciso que o transferidor esteja disposto a transferir e que o receptor esteja apto a receber a tecnologia e absorver o conhecimento transferido, pois o conhecimento tecnológico deve ser recebido, desenvolvido, utilizado e melhorado por meio de tal transferência (TAKAHASHI, 2005).

O processo de TT não está baseado em apenas transferir fisicamente uma tecnologia, e sim em um conjunto de atividades capazes de fazer com que o receptor possa utilizar plenamente a tecnologia adquirida, e para isso é necessário uma boa infraestrutura e forte relação entre fornecedor e receptor da tecnologia. Em casos em que o receptor não possui qualificação para absorver totalmente as novas informações e utilizá-las efetivamente, é preciso gerar mecanismos de interação entre este e o fornecedor, interagindo setores de pesquisa e desenvolvimento, de engenharia e corpo técnico. É função do fornecedor, discernir o uso da tecnologia para as possíveis aplicações, aumentar a percepção de recursos em potencial e do retorno do investimento desta nova tecnologia, selecionar a forma e o mecanismo apropriado para a transferência de tecnologia, assim como estabelecer e utilizar mecanismos para medir o sucesso da transferência tecnológica (BRAGA JR et al., 2009).

A tecnologia transferida não pode ser a única fonte de vantagem competitiva para um receptor, pois essa tecnologia também está acessível a outras empresas competidoras em todo o mundo. Para deter uma vantagem a empresa necessita absorver conhecimento tecnológico e acumular competências baseadas na tecnologia recebida, de maneira que seus concorrentes não possam copiar (BARBOSA, 2009). As tecnologias transferidas raramente são utilizadas integralmente como na origem, e sim são adaptadas para a realidade local, mostrando que tecnologia não é definida em única vez, mas sim sofre evoluções e adaptações. Essas adaptações geram mudanças e melhorias na tecnologia que muitas vezes geram potenciais transferências (BACH et al., 2002; BOZARTH, 2006). 


\section{Distância Tecnológica}

O desenvolvimento tecnológico é diferente entre os vários países do mundo. Através da globalização, que permitiu a diminuição das fronteiras entre as nações e o aumento do intercâmbio cultural, as diferenças entre as tecnologias que cada país detém ficaram mais visíveis. A distância tecnológica está relacionada com as diferenças tecnológicas entre entidades e organizações que participam de atividades de transferência de tecnologia. A sua definição ainda não é formal, porém um conceito utilizado para relação quando entre países distintos é o de distância psíquica (REMONATO, 2011). Essa distância é definida como o conjunto de fatores que podem interferir no fluxo de informação entre o fornecedor e receptor da tecnologia, como por exemplo: diferenças de linguagem, cultura, leis e regras, sistemas políticos, etc. Quanto maior essa distância psíquica, maior é a dificuldade de se construir relacionamentos entre os agentes (JASIMUDDIN et al., 2012).

Em processos de transferência de tecnologia, as distâncias física, cultural e organizacional entre os agentes participantes podem afetar diretamente no fluxo constante de conhecimento, que é fator vital para o sucesso da transferência. Quando essa distância ocorre é de sua importância adotar um sistema de gestão do conhecimento eficaz, pois seu principal objetivo é maximizar a exploração dos recursos dentro de organizações separadas no tempo e espaço (AMBOS e AMBOS, 2009).

Wisner (2003) cita que os problemas observados com mais frequência quando da transferência de tecnologias, especialmente entre países, referem-se àqueles relacionados aos contextos geográfico, industrial, às limitações de natureza comercial, financeira e aos fatores humanos, consequentemente aumentando a distância tecnológica entre os agentes.

- Contexto geográfico: evidencia as diferenças existentes que podem comprometer o bom funcionamento do sistema de produção e possibilitar ao país importador efetuar as adaptações necessárias e identificar problemas locais, como por exemplo, aspectos climáticos (SANTOS et al, 1997). As intervenções e interações sociais são facilitadas pela proximidade geográfica, o contato direto aumenta a compreensão do contexto e melhoram as tomadas de decisões, pois intensifica a formação de redes sociais e profissionais, aumenta a velocidade dos feedbacks e frequência dos contatos, e consequentemente a qualidade e quantidade de informações trocadas (VILELA JR., 2010).

- Contexto industrial: de sua consistência pode depender o êxito ou fracasso do projeto. Fazem parte dele fornecedores de matéria-prima, disponibilidade de peças de reposição, pessoal qualificado para assistência técnica e outros (SANTOS et al., 1997; WISNER, 1994).

- Contexto social: refere-se à forma como os indivíduos, empresas e instituições interagem 
uns com os outros. Em processos de internacionalização, essas diferenças ficam muito mais acentuadas, pois os costumes e culturas vão aumentando à medida que as distâncias aumentam também (REMONATO, 2011). Inclui no contexto social a disponibilidade de recursos humanos qualificados, o que nem sempre acontece, exigindo por parte da empresa dispêndio adicional de valores para qualificação profissional (SANTOS et al., 1997).

Segundo Cantisani (2006), que desenvolveu um modelo evidenciando os fatores inibidores de um processo de inovação e suas interações, sendo este apresentado na Figura 1.

Figura 1 - Relacionamento entre controle da tecnologia e abordagem da Transferência de Tecnologia

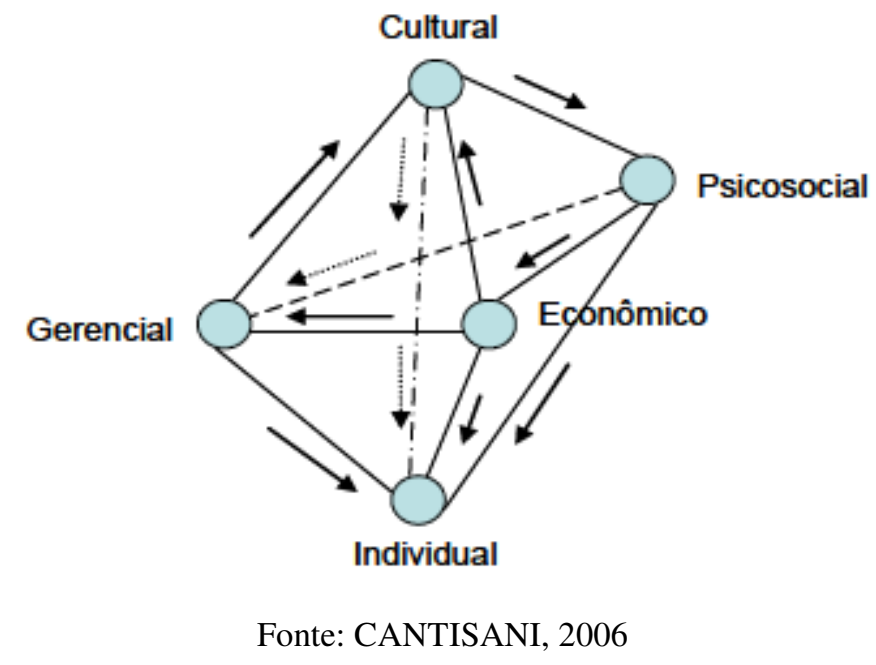

Os fatores econômico e gerencial são inibidores com maior facilidade de serem trabalhados, porém o fator comportamento psicossocial é o com maior grau de dificuldade de mudança nos grupos. Quando um comportamento é adotado por um grande número de pessoas, por muito tempo, este passa a ser parte integrante da cultura do grupo, tornando-se um paradigma (CANTISANI, 2006). Sendo assim, a cultura das pessoas envolvidas em um processo produtivo podem dificultar processos de inovação dentro de uma indústria, e este fato é agravado quando os indivíduos não estão acostumados com mudanças ou com o avanço da tecnologia.

As entidades participantes de um processo de transferência de tecnologia precisam ser capazes de transferir conhecimento dentro de redes organizacionais caracterizadas pela separação através do tempo, espaço, cultura e língua. Embora o advento da moderna tecnologia da informação que reduz ou até elimina alguns dos desafios inerentes colocados pela distância, tais como comunicação ou coordenação de custos, as diferenças de cultura e língua podem dificultar o sucesso da transferência (AMBOS e AMBOS, 2009).

Em processos de transferência tecnológica de países industrializados para países em desenvolvimento, geralmente, o receptor não está preparado para a assimilação e utilização plena da nova tecnologia (BRAGA JR et al., 2009). Isso acontece pela diferença de infraestrutura entre ambas, para que o processo ocorra a contento do fornecedor e do receptor. 


\section{Material e Métodos}

Este trabalho se caracteriza como uma pesquisa descritiva-exploratória que investiga, dentro de um contexto real, um fenômeno contemporâneo. Configura-se como um estado de caso simples, pois permite compreender a complexidade e a natureza de processos que estão ocorrendo.

Foram utilizados procedimentos técnicos de pesquisa bibliográfica, com a finalidade de entender as possíveis influências da distância tecnológica em processos de transferência de tecnologia.

A coleta de dados foi realizada através de pesquisa documental em fontes primárias e secundárias, onde a aproximação do objeto de estudo aconteceu por intermédio de buscas nos registros da empresa e observações participativas na rotina da indústria. Posteriormente foram realizadas entrevistas diretas com gestores, que possuem conhecimentos aprofundados das práticas empresarias e processos de produção da indústria em questão.

As entrevistas e os dados qualitativos foram avaliados segundo o método de análise do discurso.

\section{A empresa}

A empresa, base para o estudo, atua no ramo alimentício com quatro unidades produtivas distintas, para produção de massas, biscoitos e refresco em pó, além de estar em processo de implantação de uma nova linha de produção, para um produto distinto. Conta com planta industrial de $24.000 \mathrm{~m}^{2}$ e mais de 500 funcionários diretos. Sua produção cresce em ritmo acelerado, devido ao ganho de mercado e, consequentemente, a empresa vem investindo em tecnologia para atender a demanda.

\section{Resultados}

\section{O processo de transferência tecnológica na indústria estudada}

Com a crescente demanda por produtos de qualidade a indústria em questão está buscando em novas tecnologias a solução para manter-se estável e atingir uma maior fatia do mercado. Essas tecnologias, na grande maioria, são oriundas de outras regiões do país, e até mesmo de outros países, e proporcionam um grande crescimento, tanto em produtividade como em lucros.

Observa-se, por intermédio de entrevistas com gestores industriais, que a empresa não possui uma estratégia formal para adquirir novas tecnologias, assim como para transferir o 
conhecimento tácito e explícito envoltos nesse processo.

Os processos de transferências de tecnologia que acontecem na empresa são comandados pelos fornecedores, que realizam a venda e posteriormente prestam assistência técnica. A relação entre fornecedor e receptor é de parceria, pois o primeiro é o responsável pela difusão e implementação da nova tecnologia adquirida. O meio utilizado pelo fornecedor é o de treinamento das pessoas que estarão envolvidas diretamente com a nova tecnologia.

A aquisição de novos equipamentos/tecnologia inicia a partir de uma necessidade. Em seguida, os gestores buscam conhecer, no mercado fornecedor, as soluções disponíveis, assim como as novidades. Após determinar a tecnologia a ser adquirida iniciam-se os tramites legal para compra.

Os estudos de viabilidade para a implantação de novos equipamentos acontecem de forma esporádica, onde na maioria dos casos ocorrem apenas adaptações de layout e aos equipamentos já em uso.

Da compra até a utilização do novo equipamento não existe uma sequência de passos, sendo uma atividade padrão apenas o treinamento para os funcionários que terão contato direto com a nova tecnologia. Essa ausência de procedimentos técnicos padrões dificulta o controle de forças e fraquezas do processo de transferência sofrido por essas.

\section{Distância tecnológica e a transferência de tecnologia na empresa}

Desde o processo de compra até a instalação e utilização da nova tecnologia, diante dos fatos observados e informações coletadas, há inúmeras dificuldades quando há uma distância tecnológica entre os agentes de transferência da tecnologia. Dentre essas dificuldades podemos citar: comunicação, cultura, clima, infraestrutura, mão de obra, etc.

Em processos de implantação de uma nova tecnologia o idioma tem influência direta para o alcance do sucesso. Além da linguagem escrita do manual, os comandos manuais do equipamento também devem estar de acordo com o idioma local, para facilitar a operação do novo equipamento, pois os operadores de máquina não possuem instruções suficientes para o entendimento de idiomas distintos. Caso isso não seja possível, é preciso o treinar os funcionários, que estarão em contato direto com o equipamento, com noções básicas do idioma em questão, para facilitar tomadas de decisões em emergências.

Segundo um dos gerentes da indústria, há alguns anos atrás, um problema corriqueiro ao importar uma tecnologia era o idioma falado pelos técnicos, pois estes realizavam a instalação dos equipamentos e treinamentos da mão de obra. Atualmente esse problema já não ocorre, pois as empresas fornecedoras, na maioria das vezes, possuem representação brasileira ou enviam 
profissionais fluentes no idioma local.

Outra distância que pode comprometer os resultados esperados para a transferência de tecnologia é a de infraestrutura. Na indústria em questão, verificou-se problema com infraestrutura nas áreas em que estão instalados os fornos e/ou fritadeiras, que proporcionam calor excessivo, agravado com as elevadas temperaturas típicas do clima da região onde a indústria esta situada, que podem comprometer o funcionamento dos demais equipamentos. Os equipamentos em torno de fornos geralmente são projetados para suportar maiores temperaturas, porém os que não estão interligados aos fornos não possuem essa característica e estão expostos a temperaturas elevadas também, por estarem situados no mesmo ambiente. Esse fator compromete, por exemplo, a lubrificação da máquina, a temperatura de selagem das embaladoras, a resistência das embalagens, etc., características que muitas vezes não são avaliadas na aquisição de novas tecnologias, e dificultam a transferência desta.

Para esse problema, de temperatura ambiente das unidades de produção, foram realizadas adaptações do layout, instalação de exaustores e ventiladores, assim como modificações na estrutura física para a colocação de janelas.

A mão de obra fabril ainda é o maior problema enfrentado, quando se trata de distância tecnológica entre os agentes de transferência, pela indústria em questão. O baixo nível de instrução dos funcionários dificulta o bom funcionamento de novos equipamentos, pois estes foram produzidos para operarem através de comandos corretos e precisos, e nem sempre é isso que acontece. Isso ocorre pela dificuldade de compreensão do processo de operação, que muitas vezes é decorado pelos operados, e que em situações distintas não estão aptos a controlar o equipamento, assim como a tomar decisões em situações de emergência.

Conforme mencionado anteriormente, com base no estudo de Cantisani (2006), a cultura do grupo de pessoas envolvidas com a nova tecnologia afeta diretamente o processo de transferência. A mão de obra não especializada, e que não busca o aprendizado contínuo, impõe barreiras para a utilização de novos equipamentos baseados no fato de até o presente momento terem trabalhado com a tecnologia antiga sem maiores problemas.

Outra dificuldade com a mão de obra, esta relacionada com a manutenção dos equipamentos, que estes, muitas vezes, não possuem o conhecimento suficiente, como o da empresa fornecedora, e acaba por dificultar o funcionamento correto do equipamento, e consequentemente o sucesso da transferência. Essa distância entre os agentes deve ser solucionada com treinamentos mais intensos e eficazes, disponibilizados pela empresa fornecedora.

Contudo, verificou-se ainda que a indústria em questão está em pleno processo de transferência de tecnologia para implantação de uma nova linha de produção. Neste evento têm-se enfrentado inúmeras dificuldades para o efetivo funcionamento dos equipamentos transferidos, que, 
por sigilo industrial, não são divulgados os reais motivos. Porém explica-se que isso se dá devido ao não cumprimento de requisitos básicos para um processo de transferência, como o estudo da planta industrial, dos requisitos, da confiabilidade do fornecedor, etc.

\section{Conclusões}

Informações, comunicações, conhecimentos, modo de atuação e operação são distintos para cada empresa, e isso é repassado a tecnologias. Ao desenvolver uma nova tecnologia essas características são incluídas de maneira implícita e que podem acarretar em divergências com o receptor dessa, em processos de Transferência de Tecnologia.

Através dos fatos observados, na indústria em questão, é possível afirmar que as diferenças entre os agentes de transferência, fornecedor e receptor, podem provocar distúrbios no processo de propagação que podem minar e, eventualmente, levar tal processo ao insucesso.

$\mathrm{O}$ estudo de caso aponta a necessidade da indústria estuda de adotar uma política interna para transferência de tecnologia, já que a aquisição de equipamentos acontece com frequência e precisa ser eficaz para alcançar a produtividade e retornos financeiros almejados. Para isso, devemse analisar as situações levantadas e buscar soluções para evitar a reincidência dessas.

A eficiência da transferência está diretamente relacionada com o modo de como a organização receptora considera a tecnologia em relação à solução de suas necessidades e de como ela se encaixará no contexto da organização (BRAGA JR et al., 2009).

Os indivíduos devem ser o principal foco das empresas, principalmente em processo de aprendizagem tecnológica, em que o aprendizado individual deve ser expandido e transformado em aprendizado organizacional. È interessante transcrever o conhecimento tácito dos indivíduos para relatórios ou documentos, para que esse conhecimento possa ser acessado por outras pessoas (REMONATO, 2011). Dessa maneira, a indústria deve estimular que o conhecimento tácito repassado pelas empresas fornecedoras seja transformado em conhecimento explicito, através de relatórios e documentos, para que as informações estejam sempre acessíveis facilitando o aprendizado dos funcionários da indústria, assim como a solução de problemas distintos.

Em mercados de alta concorrência, uma das fontes de competitividade de uma organização é possuir funcionários dotados do conhecimento necessário para exercer suas funções na melhor maneira possível. Treinar os funcionários é uma ação de extrema importância para a garantia de excelência da empresa, e retorno em inovação e lucro. Em suma, é possível afirmar que a informação e o conhecimento são essenciais para a vantagem competitiva, quando estes são transformados pelas ações dos indivíduos, permitindo criar capacidades e habilidades desejadas pela empresa (FELKL et al., 2011). 
Em paralelo é necessário investir na capacitação da mão de obra, para que esta esteja apta a lidar com as tecnologias existentes na indústria e com as novas que virão a substituí-las. O processo de capacitação deve ser contínuo, para que todos os indivíduos sejam capazes de assimilar as novas tecnologias, assim como operá-las.

\begin{abstract}
This article was developed to determine the difficulties imposed by the technological distance between the agents, supplier and receiver processes during technology transfer in a food industry. Numerous barriers can arise in this type of process, and these can inhibit or restrict the adoption of new technology and functionality. The identification of these difficulties and allow detection of possible causes the formulation of solutions to minimize their impact. To develop the research was conducted collecting data from review literature and documents, direct observations and interviews with managers of the food industry in question. The results of the case study show that technology transfer is directly related to the distance between the technological transfer agents. These results contribute to the success of the new transfer processes in the industry scenario can be adapted according to the requirements and technology distance between supplier and receiver technology.
\end{abstract}

Key-words: technology transfer; technological distance; food industry.

\title{
Referências
}

AMBOS, T. C.; AMBOS, B. The impact of distance on knowledge transfer effectiveness in multinational corporations. Journal of International Management, v. 15, n.1, p 1-14, 2009. http://dx.doi.org/10.1016/j.intman.2008.02.002

AUTIO, E.; LAAMANENT, T. Meansurement and evaluation of technology transfer: review of technology transfer mechanisms and indicators. International Journal of Technology Management, v. 10, n. 7/8, 1995.

BACH, L. COHENDET, P.; SCHENK, E. Technology transfer from European space programs: a dynamic view and comparison witch other R\&D projects. Journal of Technology Transfer, v. 27, n. 4, p. 321-338, 2002. http://dx.doi.org/10.1023/A:1020259522902

BARBIERI, J.C. Produção e transferência de tecnologia. São Paulo: Ática, 1990.

BARBOSA, Antonio P. R. A formação de competências para inovar através de processos de transferência de tecnologia: um estudo de caso. 2009. 222 f. Tese (Doutorado em Tecnologia de Processos Químicos e Bioquímicos) Universidade Federal do Rio de Janeiro, Escola de Química, Rio de Janeiro, 2009.

BRAGA JR., E.; PIO, M.; ANTUNES, A.. O processo de transferência de tecnologia na indústria têxtil. Journal of Technology Management \& Innovation, v. 4, p. 125-133, 2009. http://dx.doi.org/10.4067/S071827242009000100011

BOZARTH, C. ERP implementation efforts at three firms: Integrating lessons from the SISP and IT-enabled change literature. International Journal of Operations \& Production Management, v. 26, n.11, p. 1223-1239, 2006. http://dx.doi.org/10.1108/01443570610705836

CANTISANI, A. Technological innovation process revisited. Technovation, v. 26, n. 11, p. 1294-1301, 2006. http://dx.doi.org/10.1016/j.technovation.2005.10.003

FELK, G. S.; BITTENCOURT, J. V. M.; MATOS, E. A. S. A. Avaliação do conhecimento de proprietários de estabelecimentos alimentícios quanto às ferramentas da qualidade. In: I Congresso Brasileiro de Engenharia de Produção (CONBREPRO), 2011, Ponta Grossa. Anais do I Congresso Brasileiro de Engenharia de Produção (CONBREPRO), 2011.

FREITAS, C. C. G.; MAÇANEIRO, M. B.; KUHL, M. R.; SEGATTO, A. P.; DOLIVEIRA, Sergio L. D.; LIMA, Luiz F. Transferência tecnológica e inovação por meio da sustentabilidade. Revista Administração Pública, Rio de Janeiro, v. 46, n.2, p. 363-384, 2012. 
HUNG, S.-W.; TANG, R.-H. Factors affecting the choice of technology acquisition mode: An empirical analysis of the electronic firms of Japan, Korea and Taiwan. Technovation, v. 28, n. 9, p. 551-563, 2008. http://dx.doi.org/10.1016/j.technovation.2007.10.005

JASIMUDDIN, S., CONNELL, N. A. D.; KLEIN, J. H. Knowledge transfer frameworks: an extension incorporating knowledge repositories and knowledge administration. Information Systems Journal, v. 22, n. 3, p. 195-209, 2012. http://dx.doi.org/10.1111/j.1365-2575.2011.00382.x

JOHANSON, J.; VAHLNE, J. The Uppsale internationalization process model revisited: from liability of foreignness to liability of outsidership. Journal of International Business Studies, n. 40, p. 1411-1431, 2009. http://dx.doi.org/10.1057/jibs.2009.24

KRUGLIANSKAS, I. Tornando a pequena e média empresa competitiva. São Paulo: Instituto de Estudos Gerenciais e Editora, 1996.

LUNDQUIST, G. A rich vision of technology transfer: technology value management. The Journal of Technology Transfer, v. 28, n. 3-4, p. 265-284, 2003. http://dx.doi.org/10.1023/A:1024949029313

OLIVEIRA, S. A.; SEGATTO, A. P. Transferência de tecnologia e conhecimento sob a lente estruturacionista: uma integração temática. Revista de Administração de Empresas [online], São Paulo, v. 8, n. 2, 2009.

REMONATO, R. L. C. A distância tecnológica na adoção de novas tecnologias no sistema de ensino de uma instituição de ensino superior em um país em vias de desenvolvimento industrial. 2011. 199 f. Dissertação (Mestrado em Administração) - Setor de Ciências Sociais Aplicadas, Universidade Federal do Paraná, Curitiba, 2011.

SANTOS, N. et al (sic). Antropotecnologia: A Ergonomia dos Sistemas de Produção. Curitiba: Genesis, 1997.

SATO, F. R. Problemas e métodos decisórios de localização de empresas. RAE-eletrônica, v. 1, n. 2 , 2002. http://dx.doi.org/10.1590/S1676-56482002000200011

TAKAHASHI, V. P. Transferência de conhecimento tecnológico: estudo de múltiplos casos na indústria farmacêutica. Gestão e Produção, São Carlos, v. 12, n. 2, p. 255-269, 2005.

THEOTONIO, S.B.; EPSZREJN, R.; SOUZA, C.G.; LEAL,M.G. e XAVIER, L. A indústria de embalagens plásticas no estado do Rio de Janeiro sob o enfoque da transferência de tecnologia. In: XXII Encontro Nacional de Engenharia de Produção, Curitiba, Anais do XXII Encontro Nacional de Engenharia de Produção, out. 2002.

VILELA JR., D. C. A criação de conhecimento em cluster industriais. 2010. 254 f. Tese (Doutorado em Administração) - Universidade Federal do Rio Grande do Sul, Porto Alegre, 2010.

WISNER, A. A inteligência no trabalho: textos selecionados de Ergonomia. 2a reimpressão. São Paulo: Fundacentro, 2003.

Submetido em 13 nov. 2012; Aceito para publicação em 20 dez. 2013. 